\title{
Implant-supported Full Mouth Rehabilitation Using Customized Non-precious Metal Casting Abutments: A Case Report
}

\author{
Seulgi Kim, DDS ${ }^{1}$, Jae-In Lee, DDS, PhD²* \\ ${ }^{1}$ Resident, Department of Prosthodontics, College of Dentistry, Wonkwang University and Institute of \\ Wonkwang dental research, Iksan, Korea \\ ${ }^{2}$ Professor, Department of Prosthodontics, College of Dentistry, Wonkwang University and Institute of \\ Wonkwang dental research, Iksan, Korea \\ *Corresponding author: Jae-In Lee, Department of Prosthodontics, Daejeon Dental Hospital, Wonkwang \\ University, 77 Doonsan-ro, Seo-Gu, Daejeon 35233, Korea. \\ Tel: +82-42-355-1151. Fax: +82-42-366-1115. E-mail: greatone@wku.ac.kr
}

\section{OPEN ACCESS}

pISSN 1229-5418

eISSN 2671-6623

Implantology 2021; 25(1): 37-48

https://oi.org/10.32542/implantology.2021004

Received: October 12, 2020

Revised: January 10, 2021

Accepted: January 21, 2021

Copyright $\odot$ 2021. The Korean Academy of Oral \& Maxillofacial Implantology

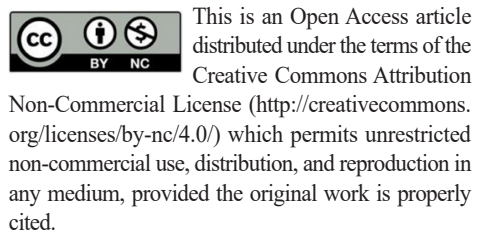

\begin{abstract}
When treating an edentulous patient, it is difficult to rehabilitate and maintain long-term functionality with an implant-supported fixed prosthesis. This is because resorption of the remaining alveolar bone may cause dissonance with the opposite arch. We present a case involving customized abutments made using a conventional casting system with cobalt-chromium ( $\mathrm{Co}-\mathrm{Cr}$ ) alloy, used to compensate for the shortcomings of prefabricated abutments. The customized abutment, used in conjunction with a cement-retained prosthesis, has shown satisfying result in both function and aesthetics during an eight-year follow-up of this particular patient.
\end{abstract}

Keywords: Alloy, Dental abutment, Dental prosthesis, Mouth rehabilitation

\section{Introduction}

Since Brånemark introduced osseointegrated implants in the 1960s, several studies have evaluated and described osseointegration in implants. Treatment with fixed prosthetic implants has shown reliable results in many edentulous patients, ${ }^{1}$ including partiallyedentulous patients or those missing single teeth. ${ }^{2}$ Furthermore, this method has been used to manage potential problems, such as periodontal disease caused by fixed or removable partial dentures. ${ }^{3}$ However, prefabricated abutments may need to be modified in some cases, such as when the implant is out of its ideal position, when the fixture is too deep, or when the angle of multiple fixtures is too wide, all of which can lead to decreased retention of the implant.

Additionally, when compared with natural teeth, the diameter of the implant fixture is narrow and its cross-section is cylindrical, therefore the emergence profile may result in 
food impaction and irritated gingiva. ${ }^{4}$ It is difficult to completely remove residual cement when the prosthetic margin is deep, and this residual cement is known to be the main cause of periodontal bone loss. ${ }^{5}$ In this situation, a customized abutment can reproduce an ideal anatomic shape, which is more suitable for the patient's condition and will allow for a more esthetic prosthesis. ${ }^{6}$

It is widely acknowledged that cobalt-chromium-molybdenum $(\mathrm{Co}-\mathrm{Cr}-\mathrm{Mo})$ alloys have excellent mechanical properties and biocompatibility. Furthermore, the increased price of gold alloys has led to the use of non-precious metal abutments, although there is a lack long-term studies available. In the present case, customized abutments fabricated using a conventional casting system with cobaltchromium $(\mathrm{Co}-\mathrm{Cr})$ alloy were used to remedy the shortcomings of prefabricated abutments, and a cement-retained prosthesis was used for full-mouth rehabilitation. There were no complications, such as periodontal bone loss or porcelain fracture of the prosthesis, during the eight-year follow-up period.

\section{II . Case Report}

The present case involves a 45-year-old female patient who visited department of prosthodontics with concerns about mobility of her residual teeth and treatment planning. During her first examination, clinical photographs, periapical radiographs, and panoramic radiographs were obtained (Figs. 1 and 2). The images showed severe generalized periodontal bone loss, and the patient was diagnosed with

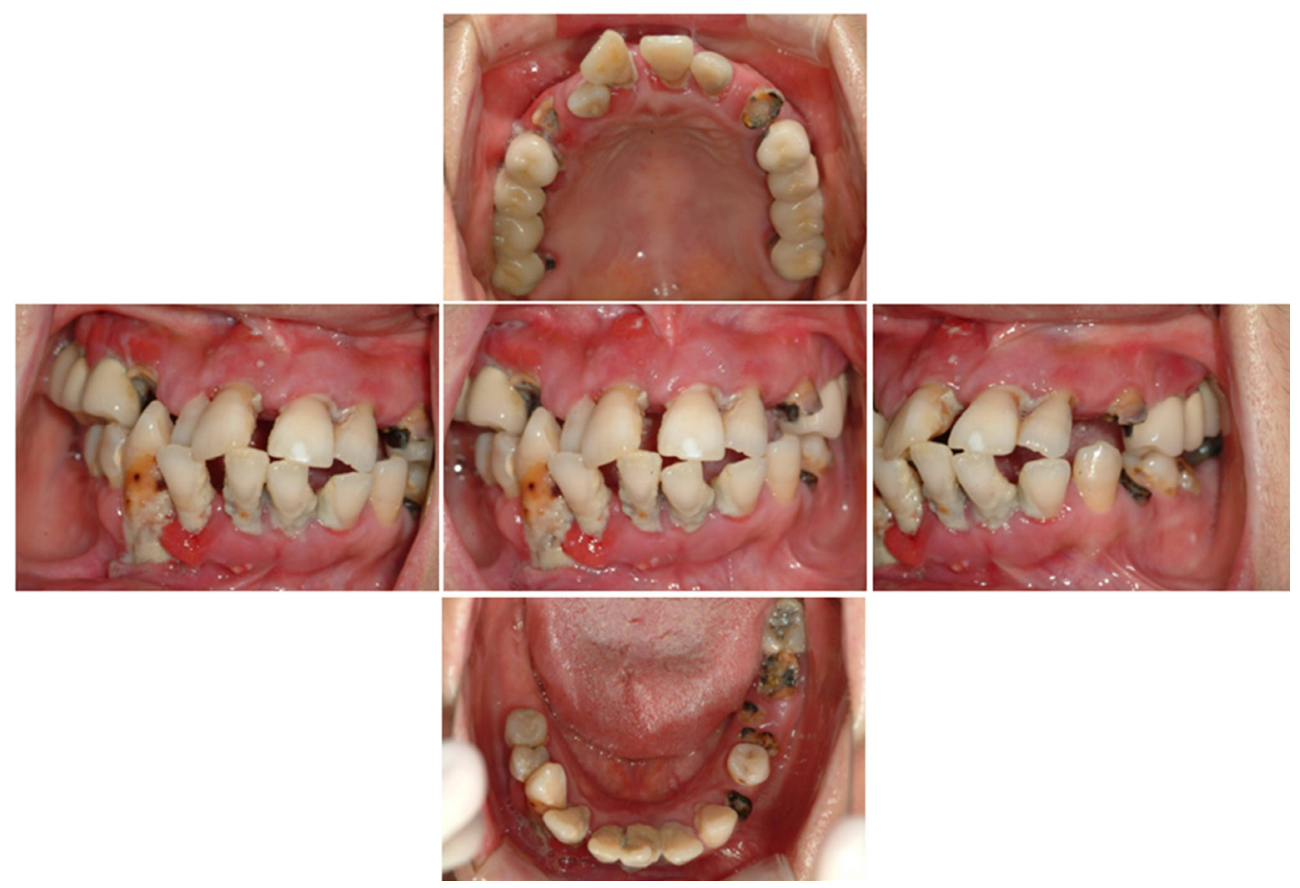

Fig. 1. Pre-operative intraoral photographs. 
chronic periodontitis. She suffered from dentophobia, so her treatment plan involved simultaneously extracting all residual teeth and placing dental implants with the patient under general anesthesia. Presurgical testing (blood test, urine test, biomechanical examination, endocrine function test, electrocardiography, and chest X-ray) were performed to assess the patient's health for general anesthesia, and all results within normal ranges.

A total of 15 implant fixtures were placed, with maxillary sinus elevation and ridge augmentation using mandibular ramus bone grafts (Fig. 3). Fixtures were placed as follows: $4.0 \times 13 \mathrm{~mm}$ on \#s 11, $13,14,15$, and $23 ; 4.5 \times 9 \mathrm{~mm}$ on \#16; $4.5 \times 13 \mathrm{~mm}$ on \#24; $4.5 \times 11 \mathrm{~mm}$ on \#s $25,26,36$, and 46; $3.5 \times 15 \mathrm{~mm}$ on \#s 33 and 43; and $3.5 \times 13 \mathrm{~mm}$ on \#s 34 and 44 (Astra, Dentsply Sirona, USA). The position and cover screws were connected.

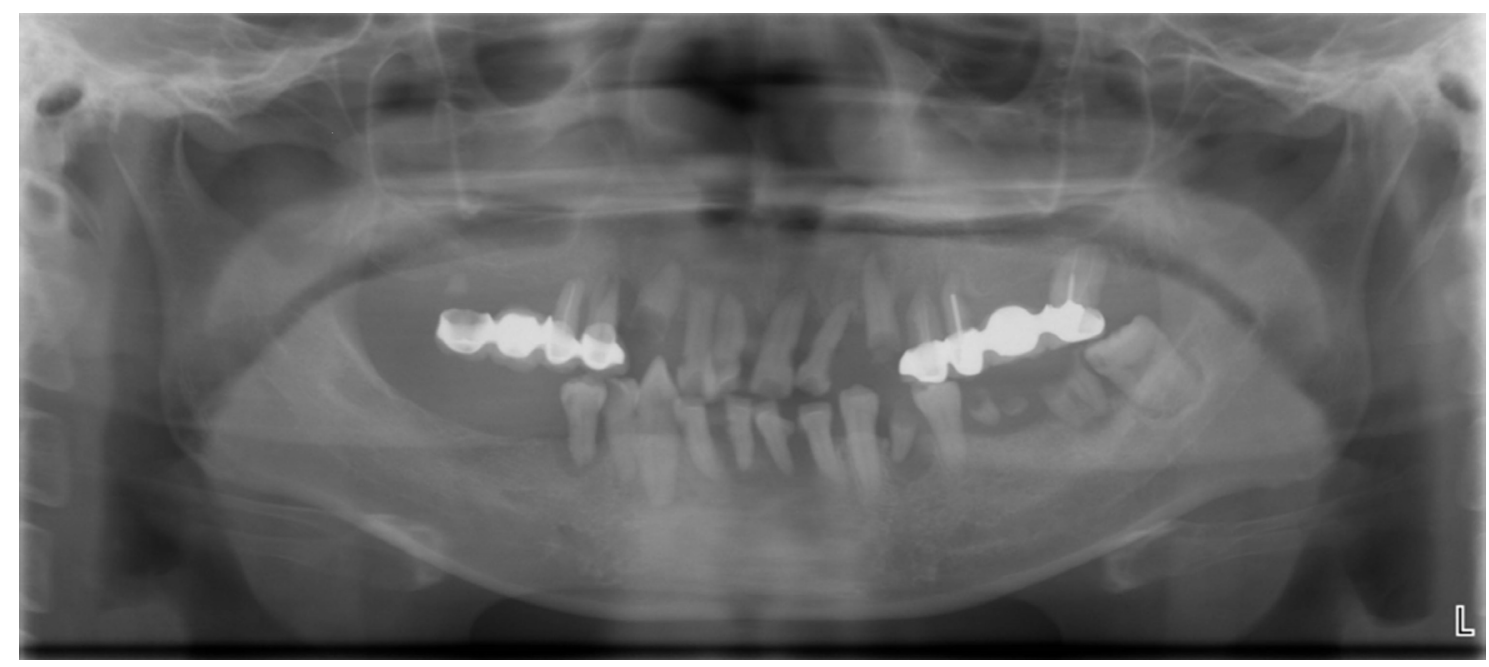

Fig. 2. Panoramic radiograph before treatment.

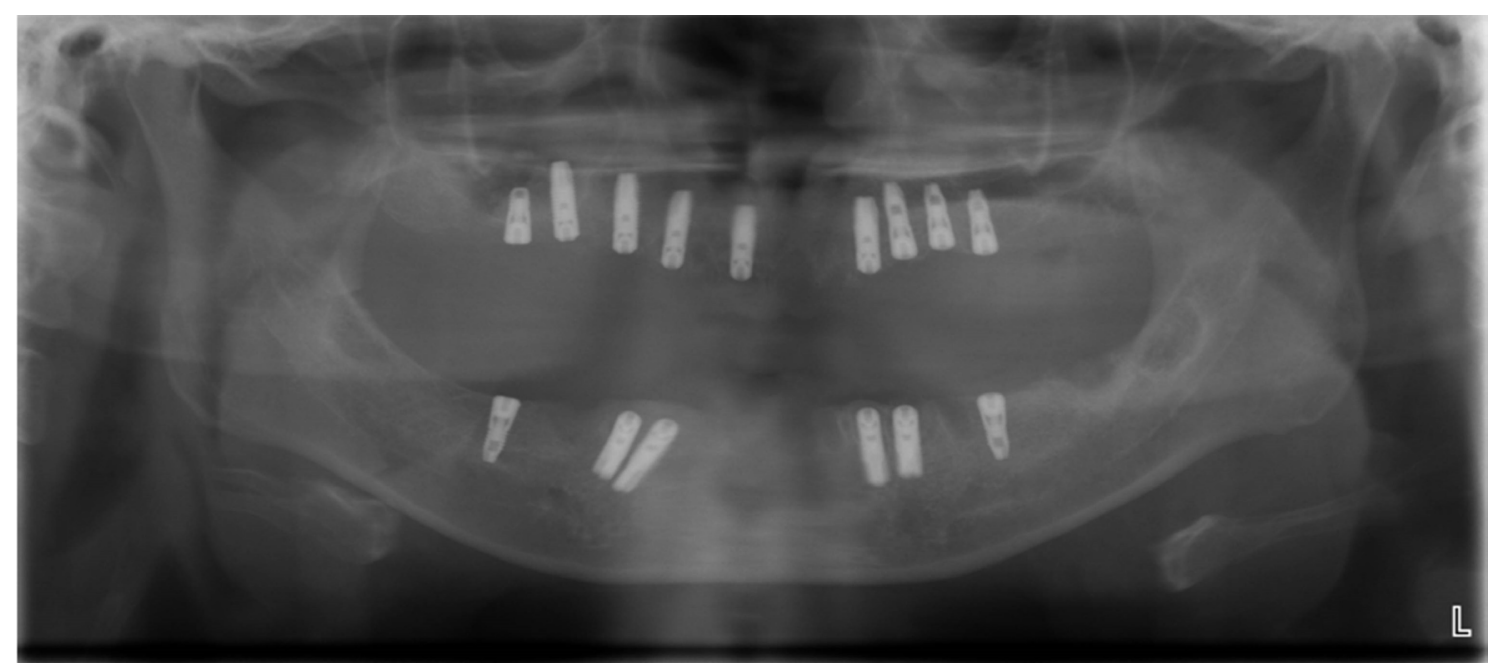

Fig. 3. Post-operative panoramic radiograph. 
Prior to extracting the hopeless teeth and placing the implants, the vertical dimensions of the jaw were measured, and were confirmed 3 weeks after surgery. Additionally, of the patient received an interim denture one month after placement of the implant posts, to improve the patient's esthetics.

The second-stage surgery was performed after a healing period of approximately six months. Alginate (Alginoplast ${ }^{\circledR}$, Heraeus Holding GmbH, Germany) was then used to take preliminary impressions two weeks after surgery, which were used to make individual trays (Figs. 4 and 5). Using the individual trays, fixture-level impressions were taken using a conventional method with vinyl polysiloxane material

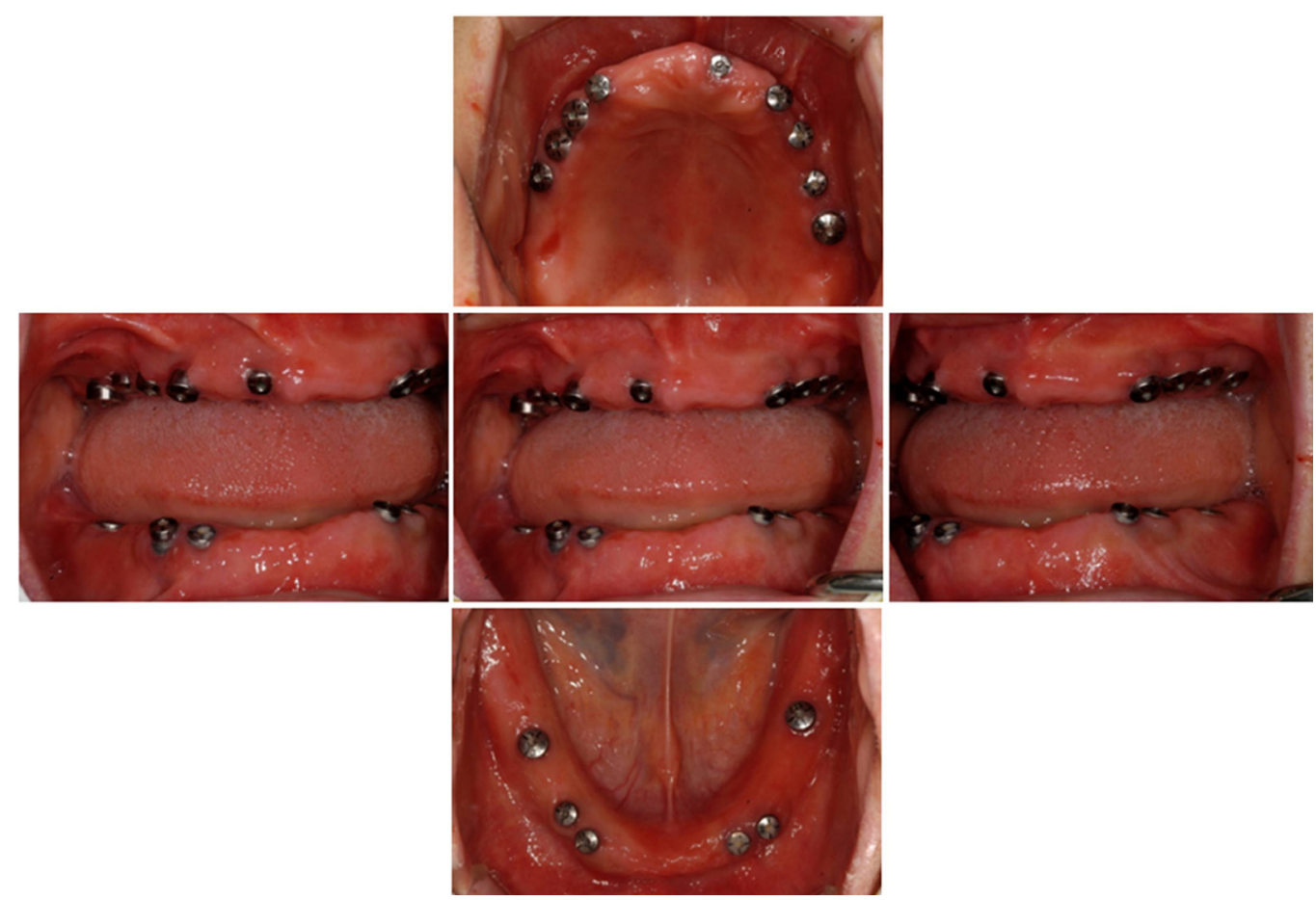

Fig. 4. Secondary surgery and healing abutment connection.

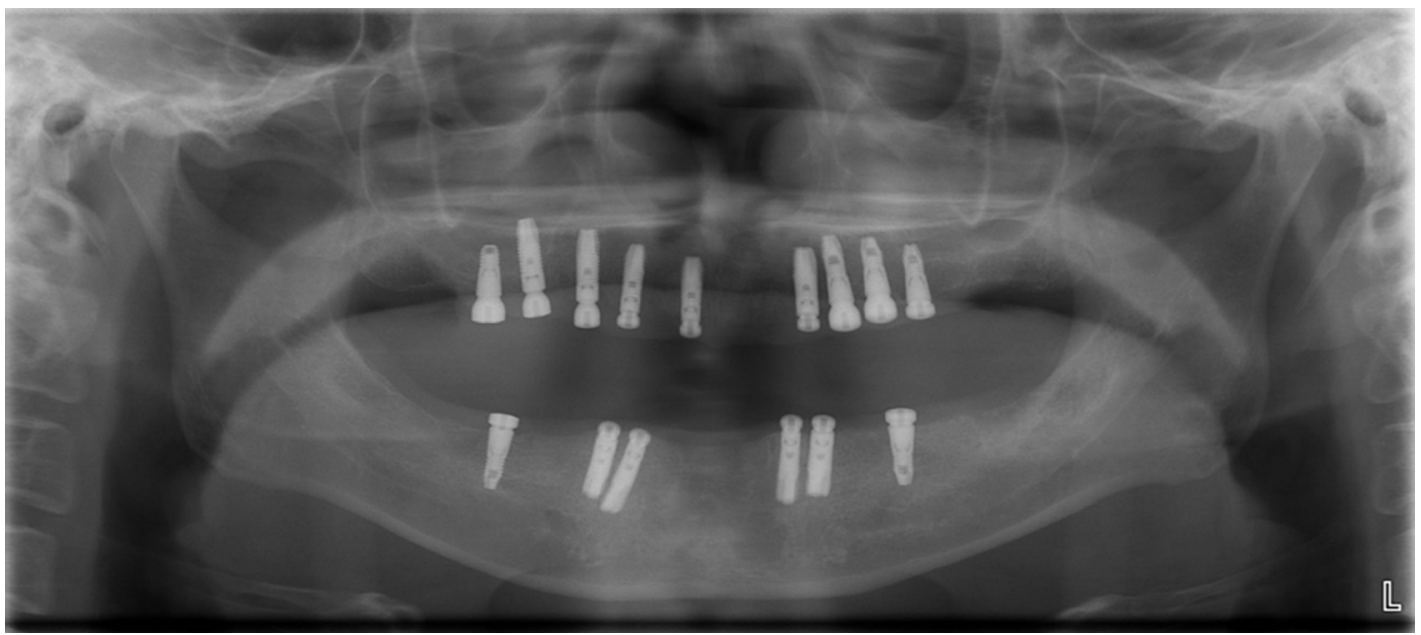

Fig. 5. Panoramic radiograph after secondary surgery. 
(Honigum ${ }^{\circledR}$, DMG, Germany). The fixture-level impressions were used to make a master cast, recording base, and wax rim (Fig. 6).

The wax rim, jaw relations, occlusal plane, lip support, and vertical dimensions (Fig. 7) were used to fabricate customized abutments with metal casting ( $\mathrm{Co}-\mathrm{Cr}-\mathrm{Mo}$ abutment, Osung, Korea), using the
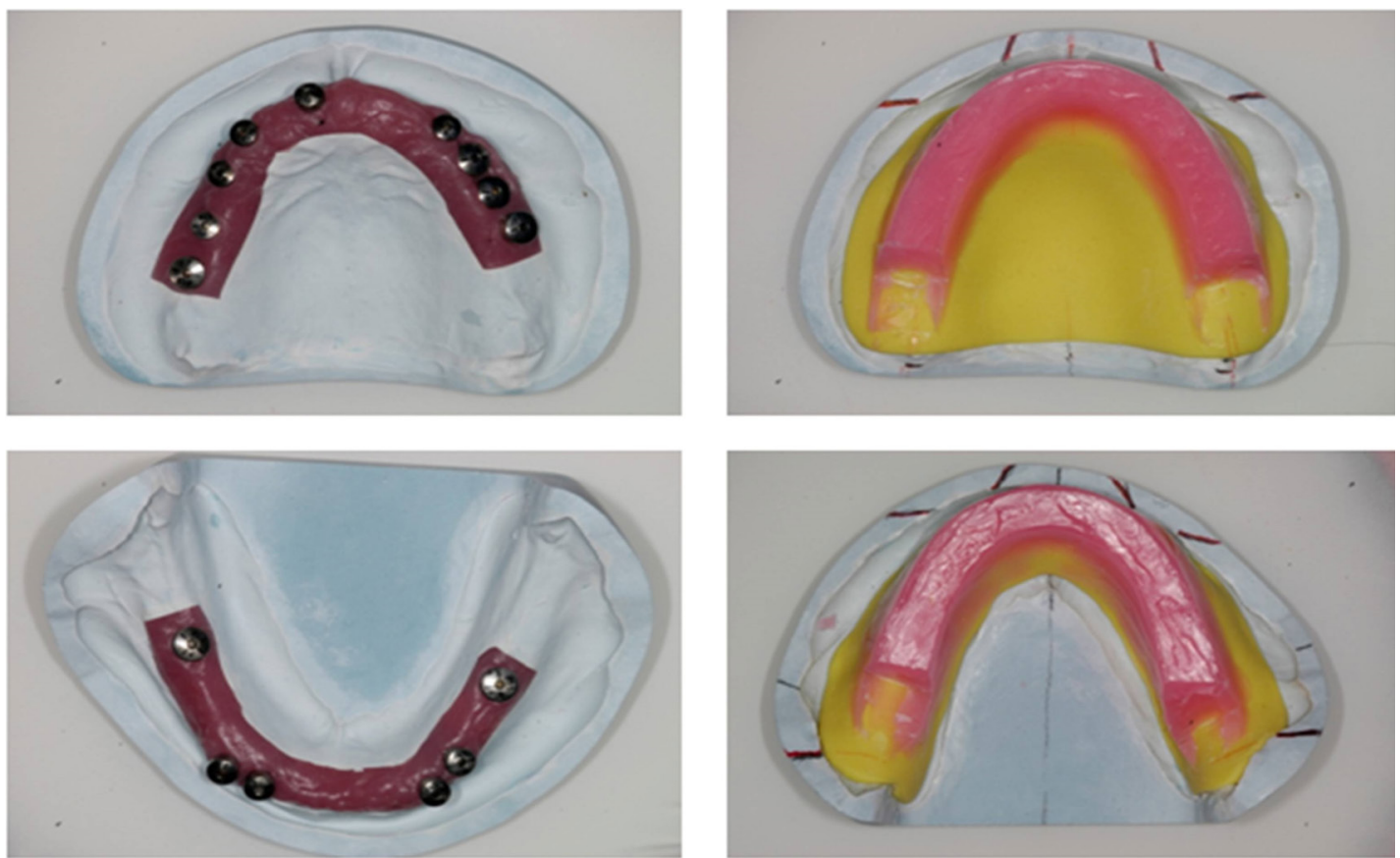

Fig. 6. Master cast and wax-rim, recording base fabrication.
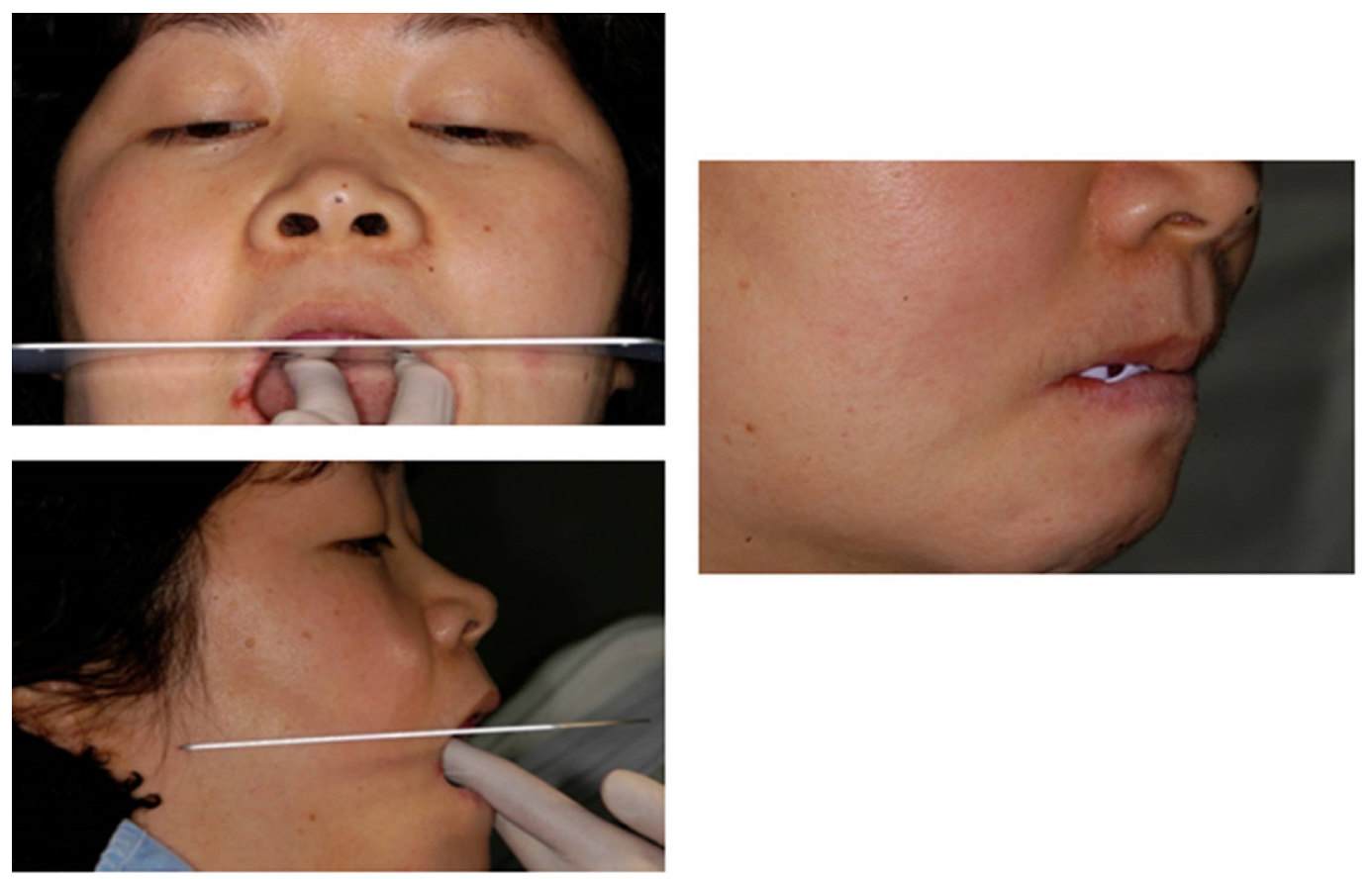

Fig. 7. Lip support, vertical dimension, occlusal plane determination. 
lost-wax technique. After casting, the oxide layer was removed with aluminum oxide, and the glass beads and abutments were highly polished, followed by fabrication of provisional prostheses (Fig. 8). The customized abutments were tightened with $30 \mathrm{Ncm}$ of torque and confirmed by periapical radiographs (Figs. 9 and 10), after which the provisional prostheses were delivered (Fig. 11).

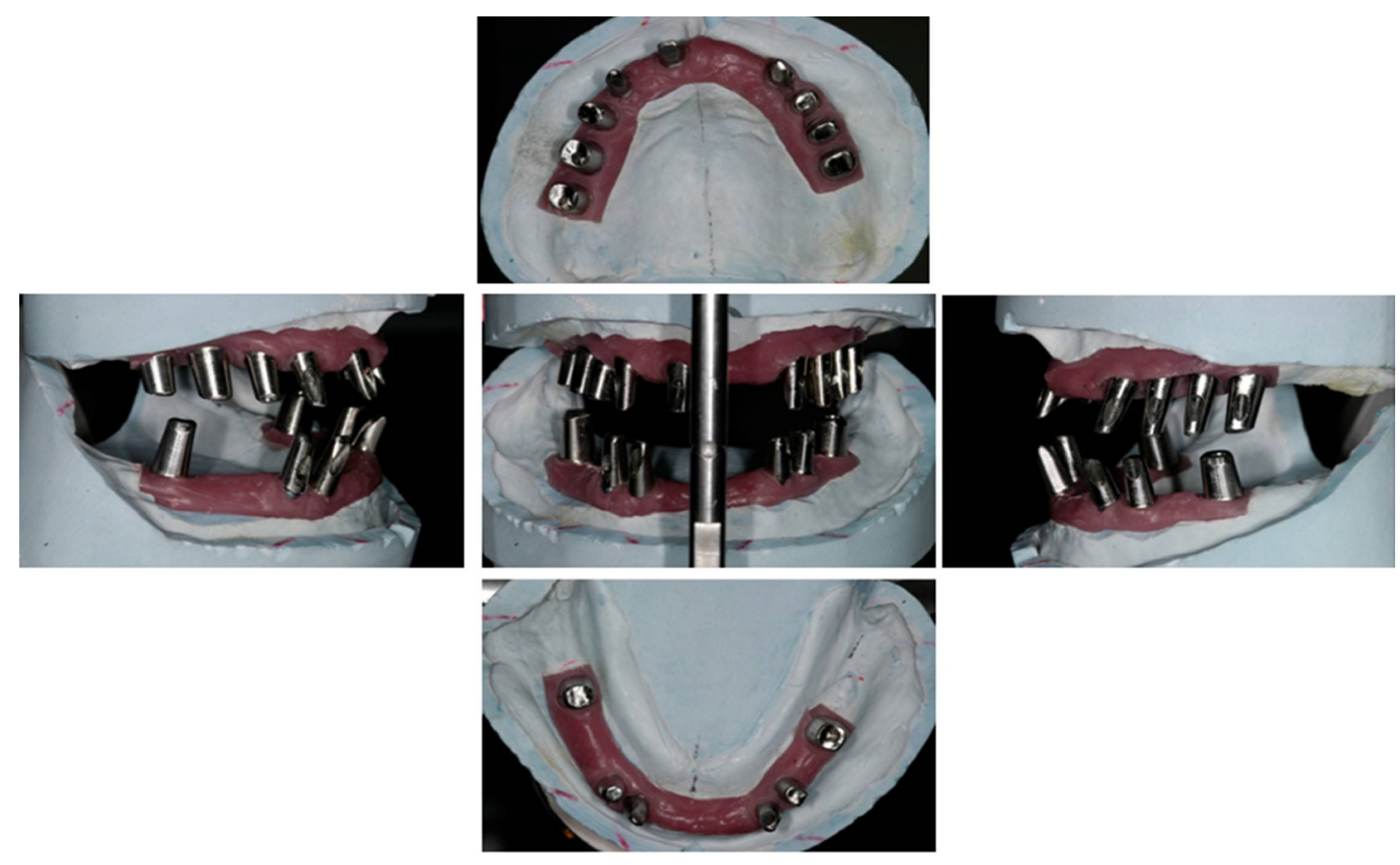

Fig. 8. Customized Co-Cr metal casting abutment fabricated.
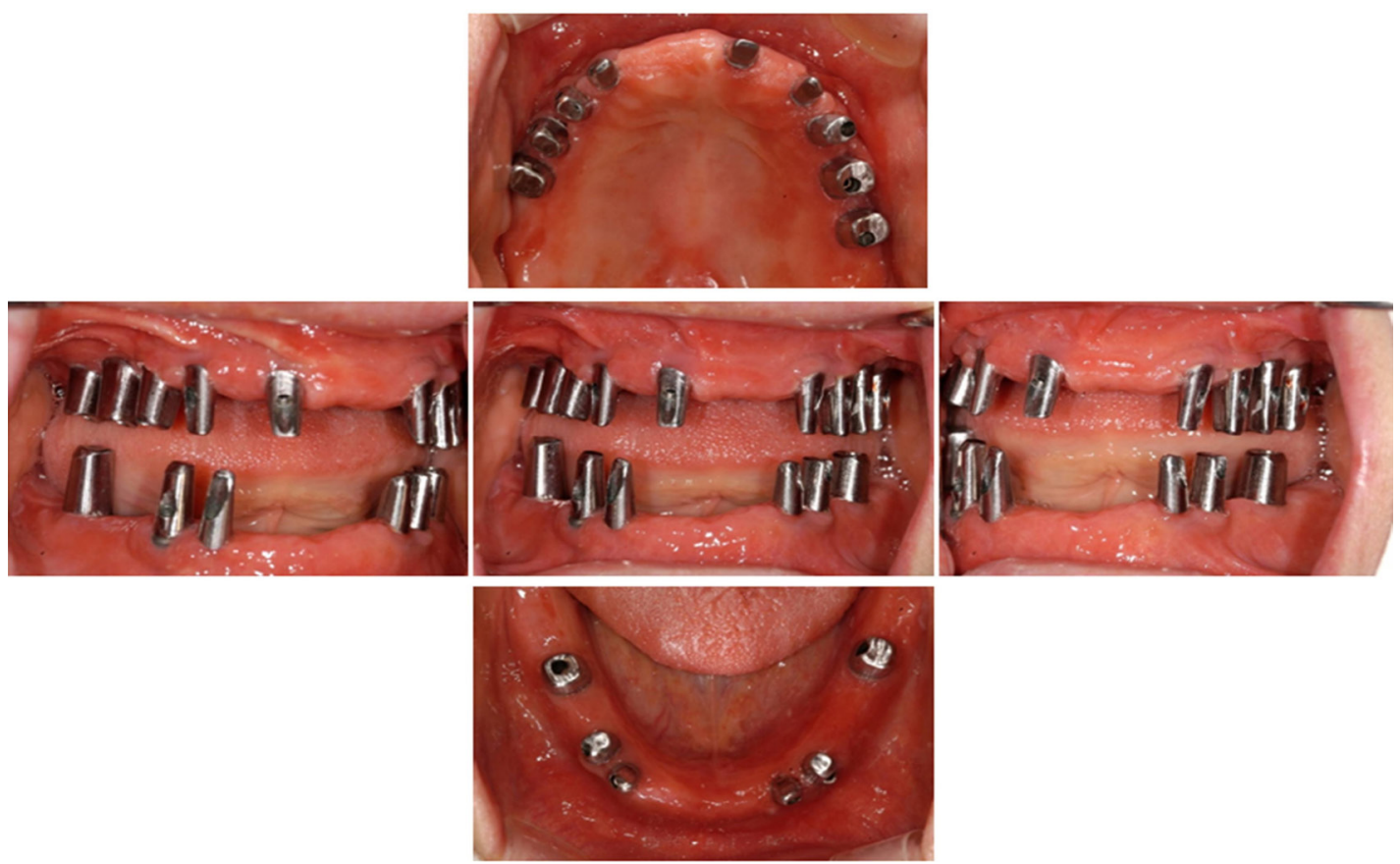

Fig. 9. Intraoral photographs after abutment connection. 
For the following two months, the patient had periodic checkups at which the provisional prostheses were adjusted and any changes were observed. During this follow-up period, the patient's oral hygiene and soft tissue reactions were observed to confirm that there were no functional problems with the prostheses, such as inadequate soft tissue reaction, muscle discomfort, temporomandibular joint disorder, mastication issues, or pronunciation discomfort, and that there were no esthetic abnormalities.

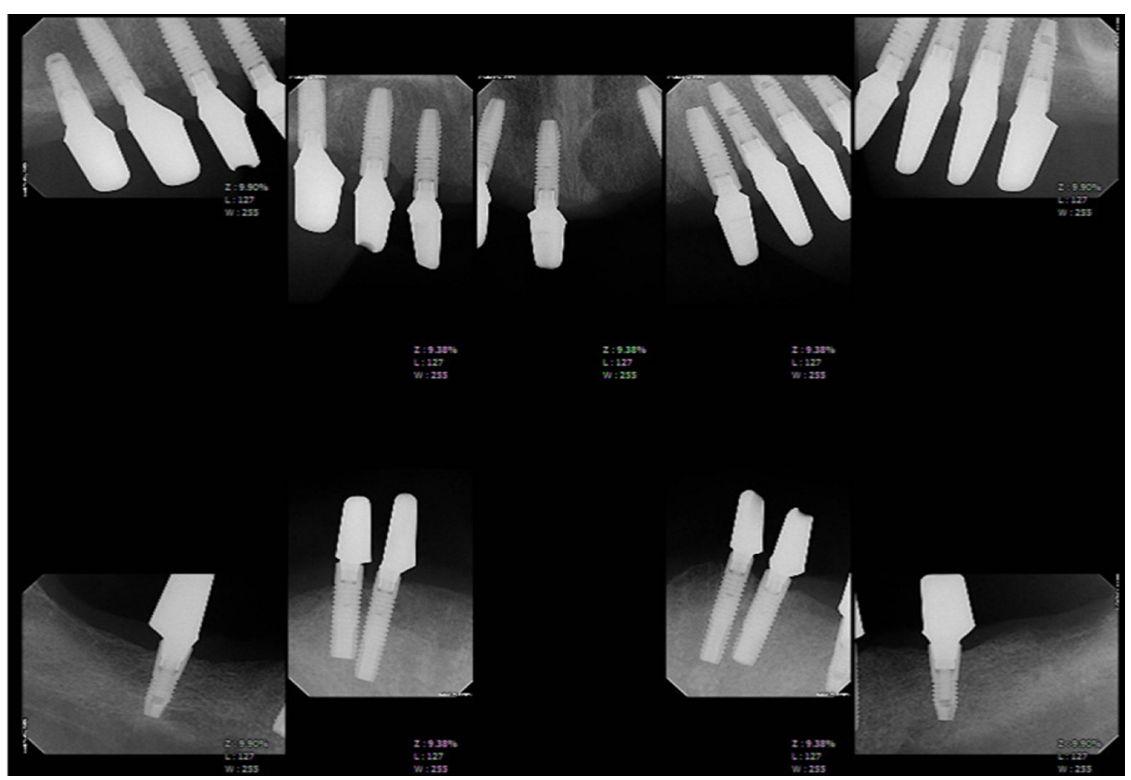

Fig. 10. Periapical radiograph after abutment connection.

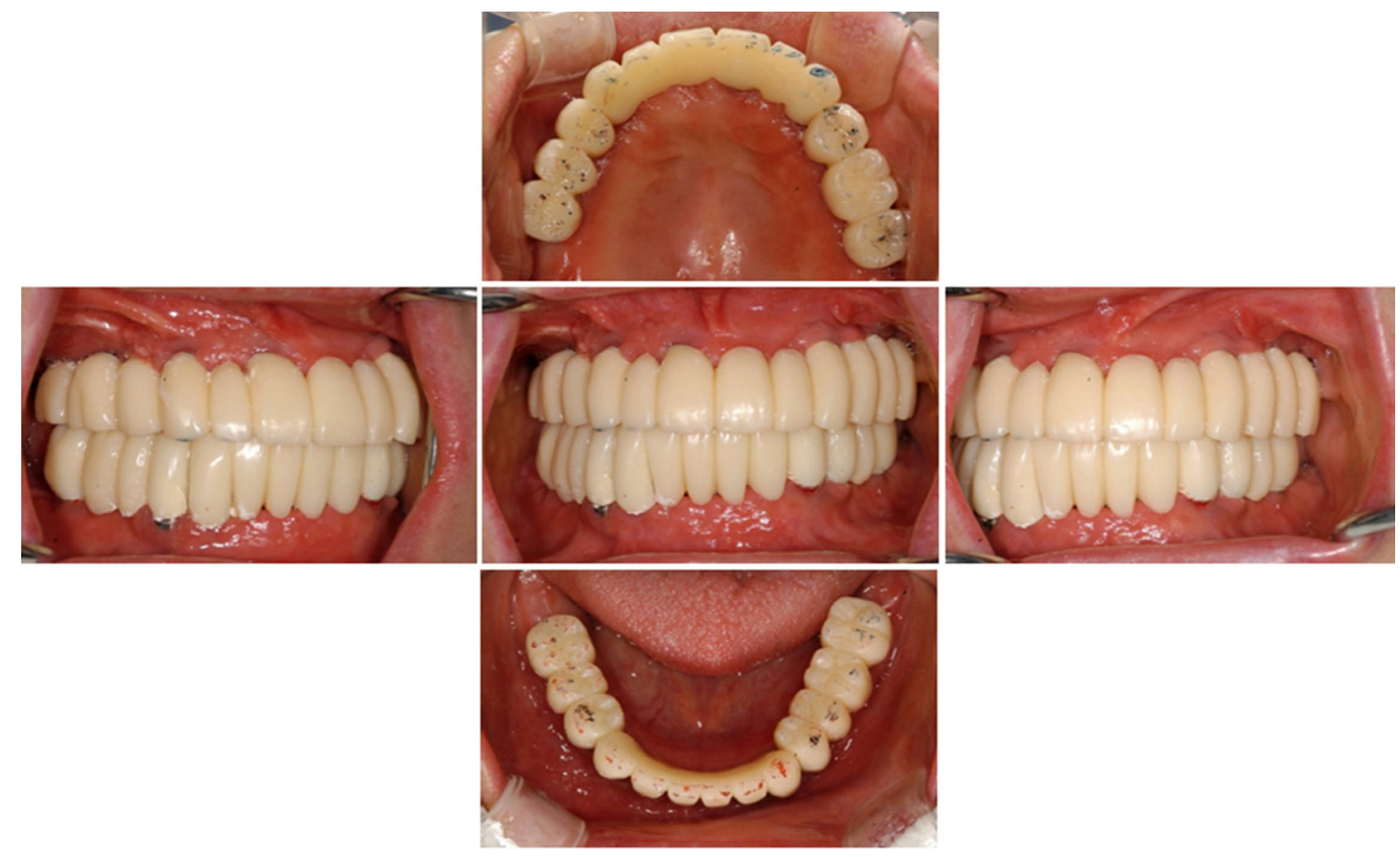

Fig. 11. Provisional restoration. 
After using the provisional prostheses for two months, the definitive impression was made using vinyl polysiloxane (Honigum ${ }^{\circledR}$, DMG, Germany), to create a master cast (Fig. 12). Using the master cast, a full-mouth wax-up and the metal framework were fabricated using conventional methods (Fig. 13).
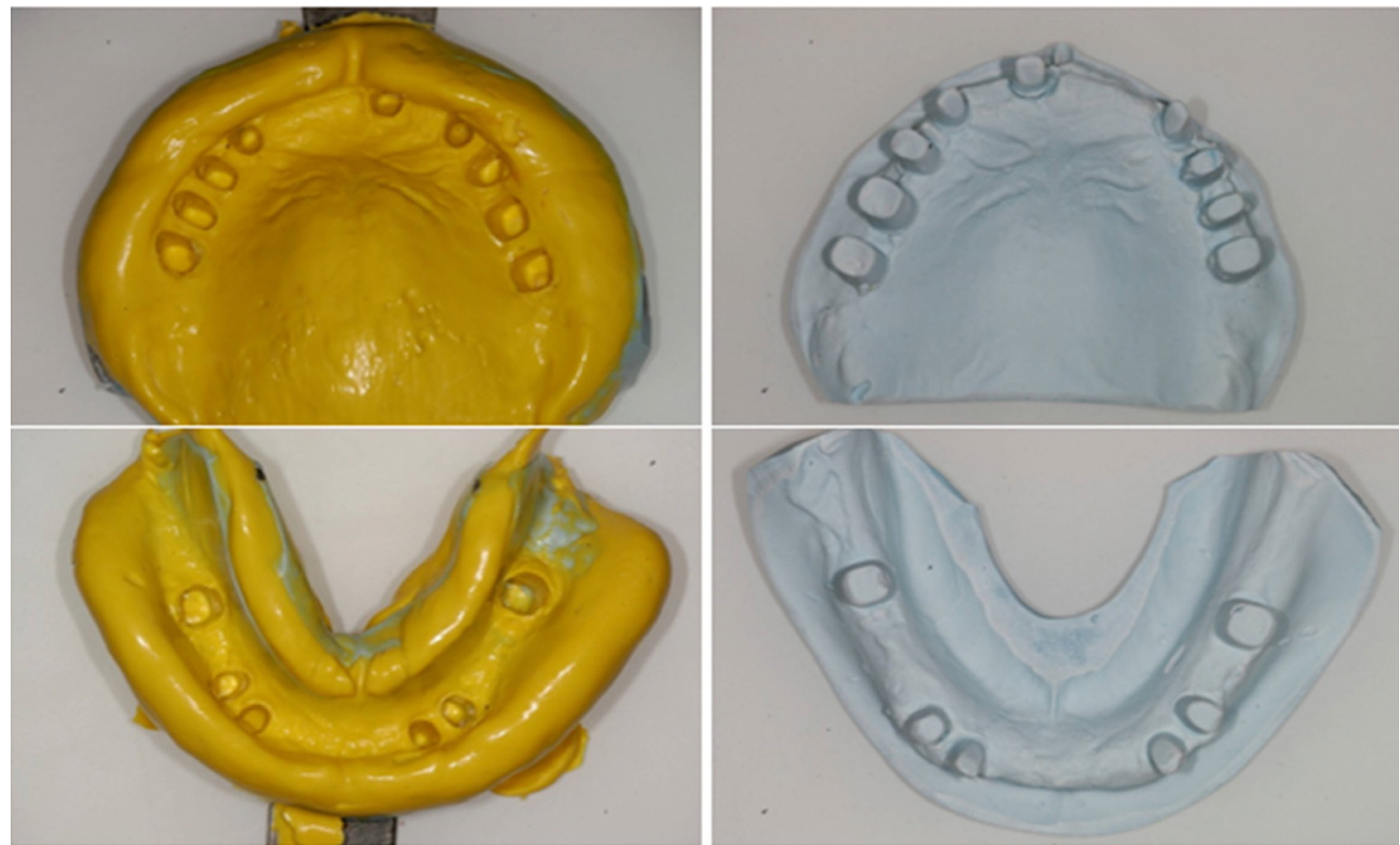

Fig. 12. Final impression taking for fixed prosthesis and master cast fabrication.

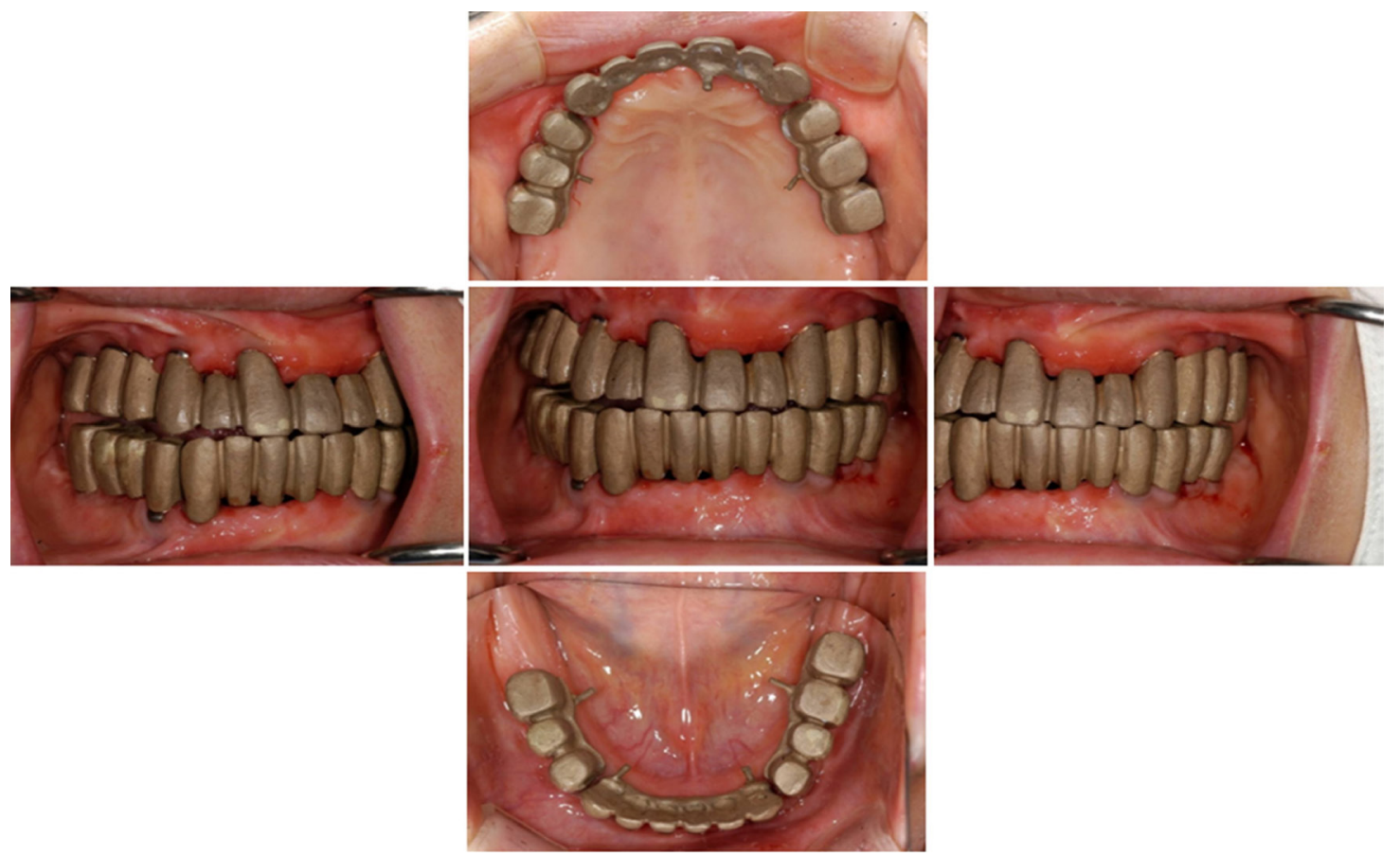

Fig. 13. Casting metal framework try-in. 
Then, the definitive prostheses were made using cement-retained porcelain-fused-to-metal bridges with splinting from \#14 to 16, \#13 to 23,\#24 to 26,\#34 to 36, \#33 to 43, and \#44 to 46 (Figs. 14 and 15). At a follow-up visit eight years after delivery of the definitive prostheses, there were no complications, such as periodontal bone loss or prosthesis fracture, on clinical photographs and radiographs (Figs. 16 and 17).

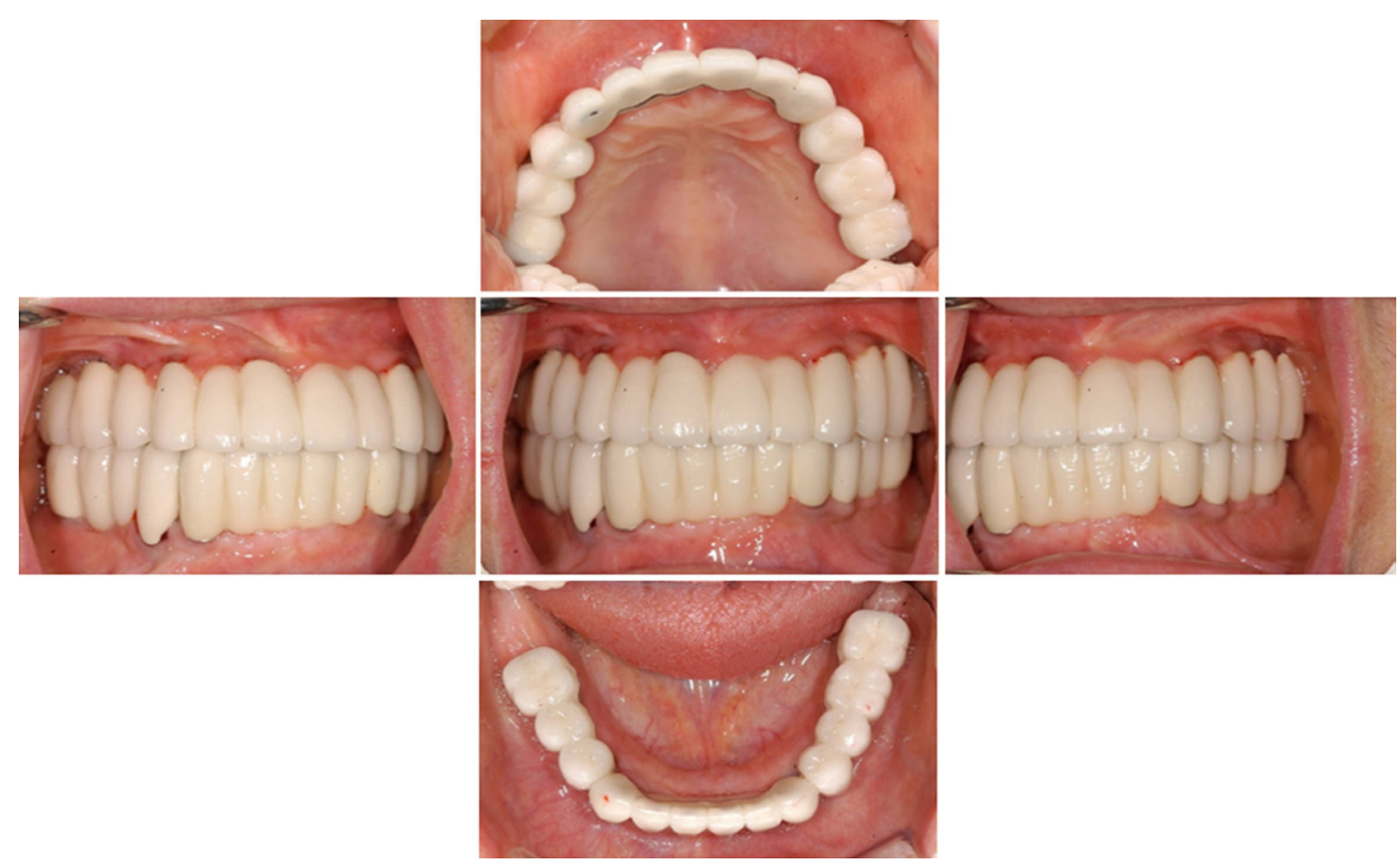

Fig. 14. Final restoration : metal-ceramic implant fixed prostheses.

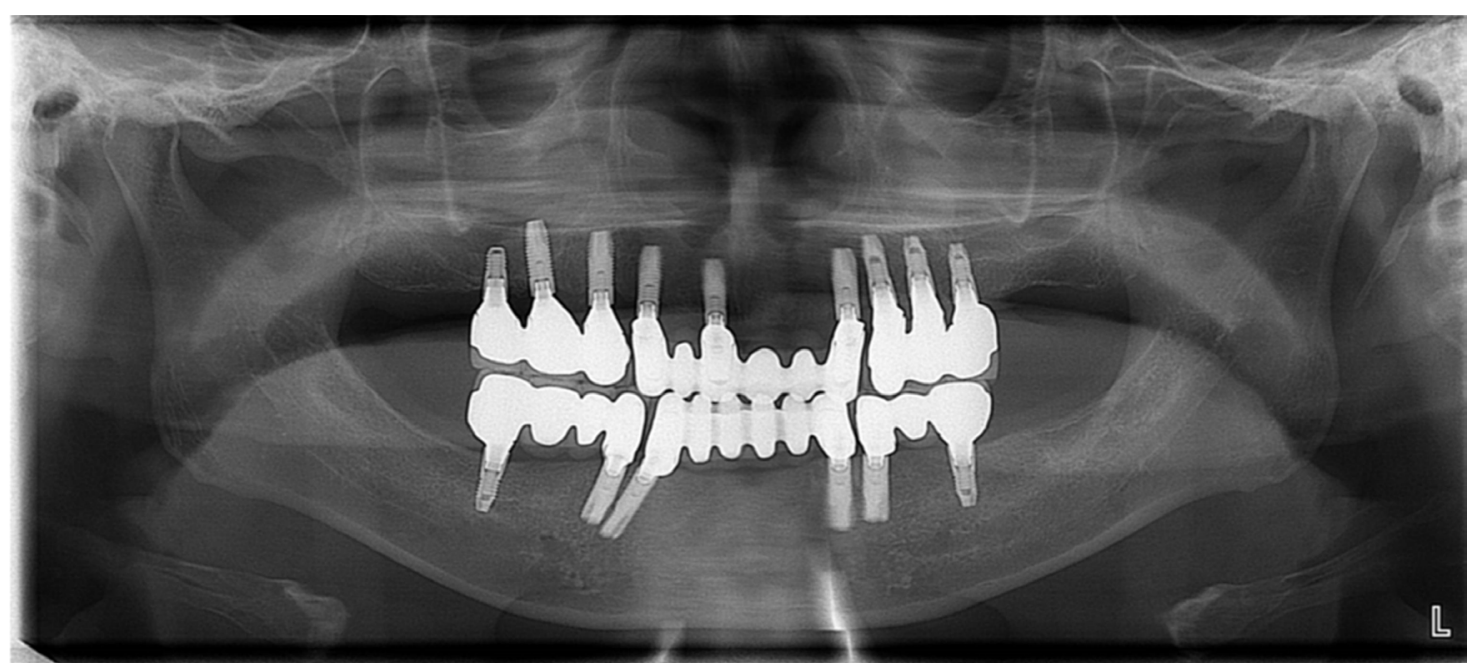

Fig. 15. Panoramic radiograph after treatment. 


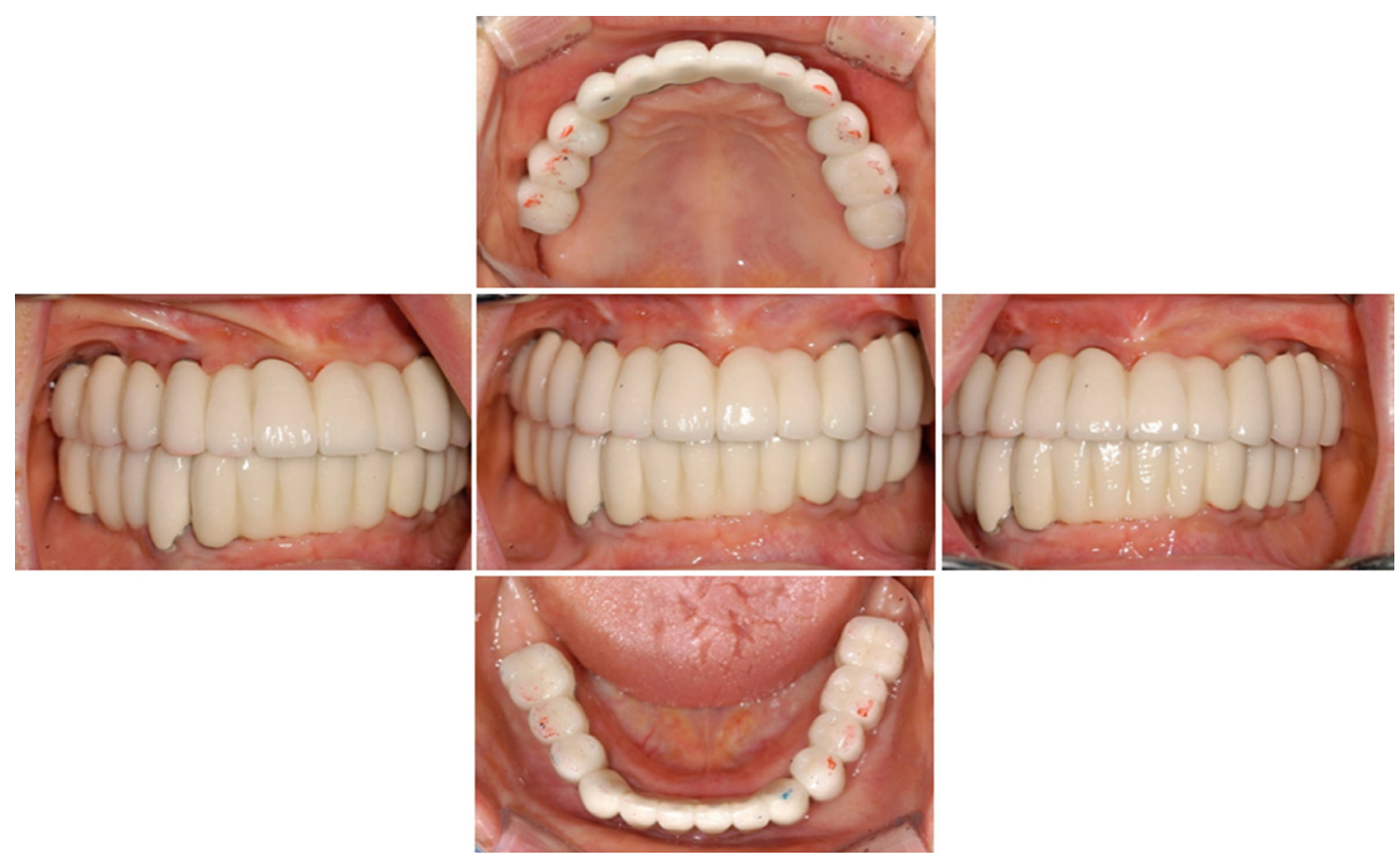

Fig. 16. Intraoral photographs : 8 yeas follow-up.

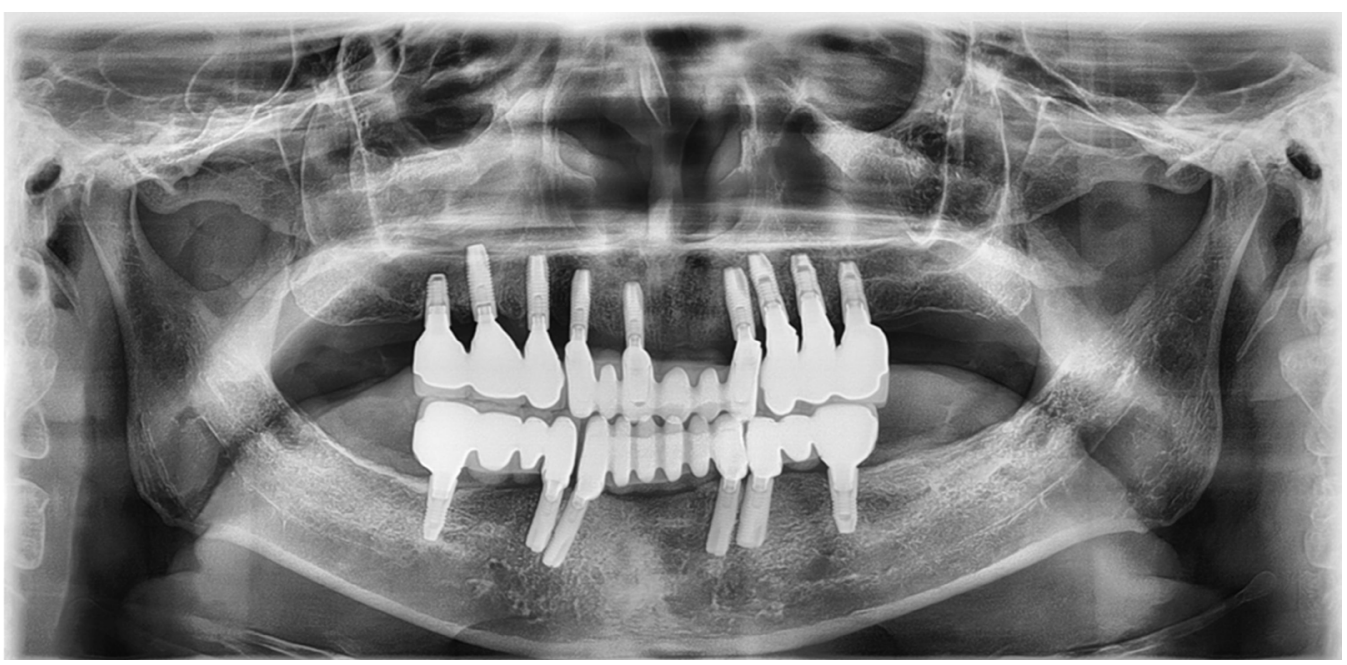

Fig. 17. Panoramic radiograph : 8 yeas follow-up.

\section{Discussion}

There are advantages to using customized abutments to create prostheses with a natural emergence profile. ${ }^{6}$ The University of California at Los Angeles (UCLA) abutment used in this case study, which was introduced in the 1980s, is a castable abutment offered with a machined gold alloy base or as a fully castable version. This type of abutment may be used for single- or multi-unit screw or cement-retained 
restorations, and may correct angles up to $30^{\circ}$ when cast as a custom abutment. ${ }^{7}$ It shows excellent soft tissue reaction, and allows for a sufficient subgingival margin with which to fabricate esthetic prostheses. ${ }^{8}$ The UCLA abutment has metal pre-made and plastic connections, and many studies have shown that metal connections, most of which are made of gold alloys, are highly accurate. ${ }^{9}$ However, recent increases in gold alloy prices have led to a subsequent increase in the clinical use of $\mathrm{Co}-\mathrm{Cr}-\mathrm{Mo}$ nonprecious metal UCLA abutments. $\mathrm{Co}-\mathrm{Cr}-\mathrm{Mo}$ alloy has been actively used in the field of artificial joints in orthopedics since the early 1900 s, owing to its excellent mechanical properties and biocompatibility. ${ }^{10}$

When assessing the mechanical stability of non-precious metal UCLA abutments, Lee et al. reported no significant difference in screw loosening or sinking after functional loading, compared to those made with precious metal. ${ }^{11}$ The problem with non-precious metal abutments is that they are less resistant to corrosion than those made with precious metals. Oh and Kim reported that galvanic corrosion may occur in the $\mathrm{Co}-\mathrm{Cr}$ alloy, although the possibility and risk of corrosion developing were not great. ${ }^{12}$ However, galvanic corrosion may accelerate corrosion at the junction of the implant and the abutment. This requires further study to observe changes in the properties of the non-precious metal UCLA abutment surface due to corrosion, and this case will require further observation over a longer period of time. There was no statistically significant difference in the removal torque value between $\mathrm{Co}-\mathrm{Cr}-\mathrm{Mo}$ and gold abutments in the tapered internal implant system. However, further consideration and long-term studies of the biological aspects are needed. ${ }^{13}$

In the present case study, there were no complications such as loss of the surrounding bone at the implant fixture or fracture of the prostheses during the eight-year period of observation, and no complications, such as corrosion of joints that are feared in non-precious metal alloys have occurred. However, it is thought that regular oral hygiene maintenance is necessary to minimize post-implant complications.

\section{IV . Conclusion}

In the case of full mouth rehabilitation using implants, satisfactory esthetic and functional results with a reliable long-term prognosis can be obtained through the use of customized abutments. Currently, a variety of materials are used to fabricate customized abutments. The patient presented above has a stable prognosis in both esthetics and function after the use of non-precious metal alloys to cast customized abutments. 


\section{Acknowledgement}

This work was supported by the funding of Wonkwang University in 2020.

\section{References}

1. Adell R, Eriksson B, Lekholm U, Branemark PI, Jemt T. A long-term follow-up study of osseointegrated implants in the treatment of totally edentulous jaws. Int J Oral Maxillofac Implants 1990;5:347-59.

2. Jemt T, Lekholm U, Adell R. Osseointegrated implants in the treatment of partially edentulous patients: a preliminary study on 876 consecutively placed fixtures. Int J Oral Maxillofac Implants 1989;4:211-7.

3. Haas R, Mensdorff-Pouilly N, Mailath G, Watzek G. Brånemark single tooth implants: a preliminary report of 76 implants. J Prosthet Dent 1995;73:274-9.

4. Lang LA, Sierraalta M, Hoffensperger M, Wang RF. Evaluation of the precision of fit between the Procera custom abutment and various implant systems. Int J Oral Maxillofac Implants 2003;18:6528.

5. Sumi T, Braian M, Shimada A, Shibata N, Takeshita K, Vandeweghe S, et al. Characteristics of implant $\mathrm{CAD} / \mathrm{CAM}$ abutment connections of two different internal connection systems. J oral Rehabil 2012;39:391-8.

6. Lee CJ, Yang SE, Kim SG. Evaluation of reverse torque value of abutment screws on CAD/CAM custom-made implant abutments. J Korean Acad Prosthodont 2012;50:128-34.

7. Lewis S, Beumer J 3rd, Hornburg W, Moy P. The "UCLA" abutment. Int J Oral Maxillofac Implants 1988;3:37-58.

8. Lewis S, Avera S, Engleman M, Beumer J 3rd. The restoration of improperly inclined osseointegrated implants. Int J Oral Maxillofac Implants 1989;4:147-52.

9. Carotenuto G, Palumbo M, Zarone F, Nicolais L. Characterization of the interface between prefabricated gold copings and cast dental alloy in implant restorations. Clin Oral Implants Res 1999;10:131-8.

10. Duncan LA, Labeed FH, Abel ML, Kamali A, Watts JF. Effects of thermal treatments on protein adsorption of Co-Cr-Mo ASTM-F75 alloys. J Master Sci Master Med 2011;22:1455-64.

11. Lee JS, Lee JS. Effect of various abutment systems on the removal torque and the abutment settling in the conical connection implant systems. J Korean Acad Prosthodont 2012;50:92-8.

12. Oh KT, Kim KN. Electrochemical properties of suprastructures galvanically coupled to a titanium implant. J Biomed Mater Res B Appl Biomater 2004;70:318-31.

13. Cho YS, Lee KW. Efficacy of Co-Cr-Mo UCLA Abutment for Internal Tapered Implant. Yonsei University 2014. 